\title{
TRATAMENTO DE TOLETES DE CANA-DE-AÇÚCAR PARA O CONTROLE DA PODRIDÃO-ABACAXI EM PULVERIZAÇÃO CONJUGADA AO PLANTIO MECANIZADO
}

\section{MARCELO DA C. FERREIRA ${ }^{1}$, COROLINA F. WERNECK ${ }^{2}$, SILVIO FURUHASHI ${ }^{3}$, GILSON J. LEITE ${ }^{4}$}

\begin{abstract}
RESUMO: No plantio mecanizado da cana-de-açúcar, há dificuldades em se proteger a cultura contra pragas e doenças do solo, requerendo uma tecnologia de aplicação de produtos fitossanitários que respeite o ambiente e os custos de produção. O objetivo deste trabalho foi avaliar um sistema de pulverização para controle de doenças e pragas do solo, conjugado ao equipamento de plantio mecanizado de toletes de cana-de-açúcar, tomando como alvo-indicador a podridão-abacaxi. Delineou-se o experimento em blocos ao acaso, em área de plantio comercial da variedade SP891115. A pulverização deu-se na região da calha do equipamento de plantio, por onde os toletes deslizam até o solo. Avaliaram-se o número de perfilhos brotados e a produção da cultura. Os resultados foram comparados pelo número e percentagem de perfilhos e pelo acréscimo na produção em relação à testemunha não-tratada. Com base nos resultados observados, concluiu-se que o sistema de pulverização de produtos fitossanitários conjugado ao plantio mecanizado proporcionou a recuperação da produtividade na cultura da cana-de-açúcar de até $15 \%$, na maior dose utilizada para o controle da podridão-abacaxi, demonstrando ser promissor para o tratamento de toletes e visando à proteção contra doenças e pragas de solo.
\end{abstract}

PALAVRAS-CHAVE: Thielaviopsis paradoxa, tecnologia de aplicação, aplicação localizada.

\section{TREATMENT OF SUGARCANE STEM TO CONTROL PINEAPPLE ROTTENNESS IN CONJUGATED SPRAYING TOGETHER WITH THE MECHANIZED PLANTING}

\begin{abstract}
On mechanized planting of sugarcane there are some difficulties to protect crop against pests and soil diseases, requiring spray technology of pesticides that respect the environment and production costs. This research aimed to evaluate a spraying system to control both soil pests and diseases, conjugated with a mechanized planter of sugarcane stems, taking pineapple rottenness as an indicative target. The experiment was designed in randomized blocks on a commercial field of sugarcane crop, variety SP-891115. The spraying was over a planter gutter, where stems slide down to soil. It was evaluated the number of arise and crop production. The results were compared to the number and percentage of arises and percentage of production over then check plot. It was concluded that spraying system of pesticides conjugated with mechanized planter, provided productivity recovery on sugarcane crop up to $15 \%$, on major dose applied to control of pineapple rottenness, revealing to be a promising system to stem treatment aiming to protect sugarcane crop from both soil pests and rottenness.
\end{abstract}

KEYWORDS: Thielaviopsis paradoxa, application technology, placed spray.

\section{INTRODUÇÃO}

A cultura da cana-de-açúcar está presente no Brasil desde o período colonial. Inicialmente, era utilizada para a produção de açúcar e aguardente, com grandes vantagens produtivas sobre outras matérias-primas. Na segunda metade do século XX, a cultura iniciou uma nova função, agora

\footnotetext{
${ }^{1}$ Eng $^{\mathrm{Q}}$ Agrônomo, Prof. Dr., Departamento de Fitossanidade, UNESP, Jaboticabal - SP, Fone: (0XX16) 3209.2641, mdacosta@fcav.unesp.br

${ }^{2}$ Eng ${ }^{\circ}$ Agrônomo, Departamento de Fitossanidade, UNESP, Jaboticabal - SP.

${ }^{3}$ Eng $^{\mathrm{O}}$ Agrônomo, M.Sc., Coordenador de Pesquisa e Desenvolvimento, Ishihara Brasil, Indaiatuba - SP.

${ }^{4}$ Técnico Agrícola, Departamento de Fitossanidade, UNESP, Jaboticabal - SP.

Recebido pelo Conselho Editorial em: 21-6-2007
}

Aprovado pelo Conselho Editorial em: 3-3-2008 
estratégica, que foi a produção de álcool combustível para substituir derivados de petróleo, marcando sua participação na matriz energética do País. Neste início do século XXI, o crescimento da economia mundial tem elevado a demanda por bens de consumo, sendo o açúcar um item significativo. O agravamento de problemas ambientais, cuja responsabilidade tem sido atribuída, principalmente, à queima de combustíveis fósseis, reforça a posição do álcool derivado da cana-deaçúcar como alternativa disponível e viável. Nesse contexto, a cultura tem vivido uma importante expansão de áreas produtivas, tradicionalmente nos Estados de São Paulo, Alagoas e Pernambuco, e mais recentemente no Centro-Oeste brasileiro.

Estudos incluindo o manejo de pragas e doenças para manter a produtividade da cultura, cuja produção estimada para a safra 2005-2006 foi de cerca 436.781,2 mil toneladas no Brasil (CONAB, 2005), são importantes para evitar ampliações desnecessárias das áreas de plantio.

Atualmente, os produtores estão fazendo o plantio de cana-de-açúcar em diversas épocas do ano, visando a escalonar a colheita da cultura e a melhorar o aproveitamento do parque de máquinas, do aparato industrial e dos recursos humanos. Isso tem causado o aumento na incidência de pragas e doenças desde antes da emergência das plantas do solo.

Pelo fato de a cana-de-açúcar ser considerada uma cultura semiperene, o plantio é uma atividade de extrema importância. Falhas cometidas por ocasião do plantio poderão representar até cinco anos consecutivos de produtividade comprometida. Com isso, os toletes plantados devem estar sadios e protegidos para reduzir os riscos da incidência de pragas e doenças.

Atualmente, o sistema de produção da cana-de-açúcar tende à total mecanização, visando ao aumento do desempenho operacional, desde o plantio até a colheita.

No sistema de plantio mecanizado, a cana é colhida mecanicamente e picada em toletes que são transportados diretamente para a caçamba da plantadora. De lá, são conduzidos por um elevador de esteira até uma calha, por onde deslizam direto para o sulco de plantio, aberto imediatamente antes e coberto de terra imediatamente após a sua chegada. Sendo assim, somente há possibilidade de tratar os toletes contra eventuais incidências futuras de patógenos, ou de pragas preexistentes na área, em sua trajetória até o solo.

Por serem de grande porte, as máquinas para plantio mecanizado possibilitam a instalação de acessórios para tratar os toletes, por meio de pulverizações, no momento do plantio, visando a atingir apenas o alvo e evitando o excesso de produtos no ambiente. Isso atende ao conceito de tecnologia de aplicação, pois pretende utilizar os conhecimentos científicos disponíveis para a correta colocação do produto fitossanitário no alvo, na quantidade necessária, de forma econômica e com o mínimo de contaminação ambiental (MATUO, 1990). Considera-se, ainda, que a máquina deve possuir um projeto que possibilite características operacionais e tratamento fitossanitário eficientes, medidos pelo grau de controle das pragas e doenças (BALASTREIRE, 1990).

Em plantios nas regiões Sudeste e Centro-Oeste do Brasil e entre os meses de abril e setembro, as plantas ficam mais suscetíveis à incidência de pragas e doenças devido às condições desfavoráveis do clima e do solo. Ao redor do mundo, são estimadas perdas de produção e produtividade entre 10 e $25 \%$ em função da incidência de doenças, com prejuízos de milhões de dólares, sem considerar, ainda, as perdas industriais que ocorrem durante o processamento dos colmos para a produção de açúcar e álcool (MOHANRAJ et al., 2002).

A doença denominada de podridão-abacaxi, causada pelo fungo Thielaviopsis paradoxa (De Seynes) von Höhn., tem preocupado pesquisadores e produtores, justamente quando a cana-deaçúcar é plantada nos períodos mais secos do ano, sobretudo devido ao crescimento, que é mais lento em temperaturas abaixo de $25^{\circ} \mathrm{C}$, e até nulo, abaixo de $19{ }^{\circ} \mathrm{C}$ (ALFONSI et al., 1987; CASAGRANDE, 1991).

O patógeno causador da podridão-abacaxi é incapaz de penetrar por seus próprios meios em tecidos íntegros ou por aberturas naturais da planta, somente por ferimentos. Na cana-de-açúcar, 
isso é particularmente importante, porque o corte das mudas em toletes para o plantio oferece uma porta de entrada ao fungo. Em toletes infectados, o desenvolvimento de raízes e gemas é retardado e inibido, e, em geral, os brotos morrem antes de emergirem do solo ou emergem vagarosamente, produzindo plantas fracas que são dominadas pela competição com plantas vizinhas e perdem produtividade (TOKESHI, 2005).

A estratégia mais largamente utilizada para o manejo de doenças é o uso de variedades de plantas resistentes. Porém, para algumas variedades ou doenças, isso ainda não é disponível ou eficaz e exige outros métodos de controle, dentre os quais o mais empregado é a aplicação de fungicidas (MOHANRAJ et al., 2002). O uso de produtos ou métodos de aplicação de maneira descuidada ou indiscriminada pode causar prejuízos financeiros e ecológicos, requerendo critérios quando de sua utilização.

O objetivo deste trabalho foi avaliar um sistema de pulverização de produtos fitossanitários conjugado ao equipamento de plantio mecanizado, para tratamento de toletes em sua trajetória até o solo, para controle de doenças e pragas do solo na cultura da cana-de-açúcar, tomando como indicador o controle da podridão-abacaxi.

\section{MATERIAL E MÉTODOS}

O experimento foi instalado e conduzido em um Latossolo Roxo eutrófico (Lr.1), em área de plantio comercial, localizada no município de Pradópolis - SP, latitude $21^{\circ} 21^{\prime} 34^{\prime \prime}$ sul e longitude 4803'56" oeste, no dia 20 de junho de 2005.

A variedade de cana-de-açúcar plantada foi a SP-891115, conhecida tanto por sua alta produtividade como pela ótima brotação de soqueira. É recomendada para colheita até o meio da safra, respondendo positivamente à melhoria dos ambientes de produção. Apresenta hábito semiereto e pouca fibra, floresce freqüentemente, porém com pouca "isoporização" (UDOP, 2006).

As mudas foram colhidas mecanicamente, cortadas em toletes com cerca de $40 \mathrm{~cm}$ de comprimento, transportadas e transferidas do transbordo para a caçamba da plantadora.

A plantadora já realiza as operações de plantio, sulcação, adubação (que neste experimento não foi realizada), pulverização, distribuição dos toletes e cobertura do sulco, concomitantemente, em duas linhas de plantio.

A cultura foi plantada em espaçamento de $1,5 \mathrm{~m}$ entre linhas e o número de gemas por metro foi de 18 a 20 . O número de toletes por metro foi em torno de 11 .

Não foi realizada adubação química, fazendo-se somente aplicação de torta de filtro na quantidade de 7-10 t ha ${ }^{-1}$, anteriormente ao plantio.

No início do experimento, a umidade relativa do ar esteve em torno de $83 \%$, e a temperatura, ao redor de $16^{\circ} \mathrm{C}$.

Para a instalação do experimento, optou-se por inocular o fungo Thielaviopsis paradoxa na área experimental para proporcionar a ocorrência uniforme da doença. Para tanto, foi necessário produzir colônias do fungo em laboratório. O fungo foi retirado de meio coberto com óleo Nujol, onde estava armazenado no setor de Fitopatologia, do Departamento de Fitossanidade, do Câmpus de Jaboticabal - UNESP, e aguardou-se 48 h até o início da reprodução e do crescimento micelial.

O meio de cultura utilizado foi composto por batata, dextrose e Ágar (BDA), sendo preparadas 130 placas de Petri. Após o preparo do meio, esse foi colocado nas placas para onde o fungo foi repicado e mantido em temperatura ambiente para crescimento e reprodução.

Após o crescimento completo do fungo (placa totalmente tomada), que se deu em torno de 15 dias após a repicagem, as colônias foram homogeneizadas em liquidificador, com adição de água para fazer a suspensão que foi inoculada na área experimental. 
O produto utilizado no experimento é classificado como fungicida-acaricida, pertencente ao grupo dos fenilpiridinilamina, possuindo como ingrediente ativo o fluazinam. É um fungicida de aplicação terrestre, classificado como altamente tóxico e de ação por contato (AGROFIT, 2007).

Na plantadora, foram adaptados dois bicos de pulverização por linha de plantio, sendo um para o tratamento com o fungicida e o outro para a inoculação dos fungos na área de plantio da cana-de-açúcar. Próximo à cabine de comando da plantadora, instalou-se um pulverizador munido de um tanque de $10 \mathrm{~L}$, pressurizado com $\mathrm{CO}_{2}$. O bico foi instalado sobre a calha por onde os toletes deslizam em sua trajetória até o sulco de plantio, com ângulo de $30^{\circ}$ entre o jato de calda e o tolete (FERREIRA et al., 2004).

A pulverização do fungicida nos toletes, nos tratamentos de 1 a 7 (Tabela 1), foi realizada com pontas de pulverização de jato plano, padrão contínuo, modelo TP 8004E, considerada a mais adequada para o sistema, por proporcionar boa distribuição da calda em ambas as extremidades dos toletes, regiões mais sensíveis à penetração do patógeno (FERREIRA et al., 2004). A aplicação foi localizada em operação conjugada ao plantio mecanizado, com velocidade de caminhamento de $5 \mathrm{~km} \mathrm{~h}^{-1}$, visando à cobertura total dos toletes de cana-de-açúcar no momento em que esses passaram pela calha da plantadora. $\mathrm{O}$ volume de aplicação foi de $121,3 \mathrm{~L} \mathrm{ha}^{-1}$.

TABELA 1. Dose do fungicida* e testemunhas utilizadas no experimento para controle da podridão-abacaxi na cultura da cana-de-açúcar. Fungicide rate* and check used in experiment to control pineapple rottenness on sugarcane crop.

\begin{tabular}{cccc}
\hline \multirow{2}{*}{ Tratam. } & \multicolumn{2}{c}{ Dose do Fungicida (produto comercial) } & Modalidade de Aplicação \\
\cline { 2 - 3 } & $\mathrm{L} \mathrm{ha}^{-1}$ & \% na calda & \\
\hline 1 & 0,50 & 0,41 & Pulverização com bico na plantadora \\
2 & 0,75 & 0,62 & Pulverização com bico na plantadora \\
3 & 1,00 & 0,82 & Pulverização com bico na plantadora \\
4 & 1,50 & 1,24 & Pulverização com bico na plantadora \\
5 & 2,00 & 1,65 & Pulverização com bico na plantadora \\
6 & 2,50 & 2,06 & Pulverização com bico na plantadora \\
7 & 3,00 & 2,47 & Pulverização com bico na plantadora \\
8 & & 0,25 & Imersão dos toletes na calda \\
\hline 9 & 0,00 & 0,00 & Sem fungicida e inoculada com o fungo \\
10 & 0,00 & 0,00 & Sem fungicida e sem inoculação do fungo \\
\hline
\end{tabular}

*Fluazinam $=$ produto comercial Frowncide $500 \mathrm{SC}$.

No tratamento oito, os toletes foram imersos na calda do fungicida, colocada em um tambor de 200 L. Posteriormente, foram ensacados e distribuídos manualmente nas parcelas experimentais, após a aplicação do fungo com pulverizador costal pressurizado, diretamente nas paredes do sulco de plantio. Nas parcelas que receberam a suspensão com os esporos do fungo, a densidade aplicada foi de $1 \times 10^{5}$ esporos por $\mathrm{mL}$ de suspensão.

O delineamento experimental foi em blocos ao acaso, com dez tratamentos e seis repetições. Cada parcela foi composta de quatro linhas de plantio espaçadas em 1,5 m entre si, com $30 \mathrm{~m}$ de comprimento $\left(180 \mathrm{~m}^{2}\right)$. Os blocos foram plotados lado a lado, seguindo a casualização estatística das parcelas. Foi tratado um bloco de cada vez, conforme apresentado na Tabela 1, com as respectivas doses e modalidades de aplicação.

Antes de iniciar a aplicação de cada tratamento, foram realizadas a regulagem e a calibração dos pulverizadores, coletando-se a calda em provetas. Após cada aplicação, foi realizada a troca do tanque de $10 \mathrm{~L}$ do pulverizador pressurizado por $\mathrm{CO}_{2}(400 \mathrm{kPa})$, referente a cada concentração de calda utilizada. 


\section{Avaliação do número e da percentagem de incremento de perfilhos de cana-de-açúcar}

As avaliações foram realizadas por meio da contagem in loco do número de perfilhos de canade-açúcar. As avaliações foram realizadas aos 30;60; 90 e 120 dias após a emergência das plantas do solo, não sendo considerada a qualidade dos perfilhos. A contagem foi realizada em $10 \mathrm{~m}$ centrais de cada parcela.

Os dados do número de perfilhos foram plotados em gráficos de dispersão, sendo determinados o coeficiente de correlação e a equação de regressão quadrática. A percentagem de incremento no número de perfilhos em relação à testemunha foi estimada utilizando a eq.(1):

$$
\mathrm{P}(\%)=\left(\frac{\operatorname{Tr} 100}{\mathrm{TF}}\right)-100
$$

em que,

$\mathrm{P}(\%)$ - percentagem de incremento de perfilhos em relação à testemunha sem a aplicação do fungicida e inoculada com o fungo Thielaviopsis paradoxa;

$\mathrm{Tr}$ - parcela tratada com o fungo e com as diferentes concentrações do fungicida, e

TF - testemunha sem a aplicação do fungicida e inoculada com o fungo.

Com os valores obtidos, elaboraram-se gráficos que estão apresentados nos resultados. Considerando que a ocorrência natural do fungo na área é menor do que nas parcelas em que houve a inoculação, a testemunha inoculada, mas não-tratada (TF), foi eleita como base de comparação, tornando-se igual a zero por cento, pela equação descrita, não sendo apresentada nos gráficos. A testemunha sem aplicação e sem inoculação expressa a ocorrência natural do fungo na área.

\section{Avaliação de produtividade da cana-de-açúcar}

A colheita da cana-de-açúcar foi realizada no dia 13 de julho de 2006, quando se avaliou a produtividade da cultura em função dos tratamentos para o controle da podridão-abacaxi. Nessa avaliação, as parcelas foram colhidas manualmente, seguindo o método usual, exceto pela ausência da queima. O ponteiro das plantas foi cortado de acordo com o praticado correntemente para o uso comercial da usina, sendo descartado pelos colhedores. Os colmos de cada parcela foram pesados, utilizando-se de recolhedora mecanizada munida de célula de carga modelo Transtec N-220, com capacidade de até $2.000 \mathrm{kgf}$.

Após a transformação da produtividade de $\mathrm{kg}$ por parcela para $\mathrm{tha}^{-1}$, foi calculada a percentagem de acréscimo na produtividade, conforme a eq.(2):

$$
\mathrm{C}(\%)=\left(\frac{\operatorname{Tr} 100}{\mathrm{TF}}\right)-100
$$

em que,

$\mathrm{C}(\%)$ - percentagem de acréscimo na produtividade, em toneladas por hectare, em relação à testemunha sem a aplicação de fungicidas e inoculada com o fungo Thielaviopsis paradoxa;

$\mathrm{Tr}$ - parcela tratada com o fungo e com as diferentes concentrações do fungicida, e

$\mathrm{TF}$ - testemunha sem a aplicação de fungicidas e inoculada com o fungo.

Assim como no cálculo da percentagem de perfilhos, a testemunha que não recebeu a aplicação de fungicidas, foi eleita como base de comparação e tornou-se igual a zero por cento, pela equação descrita, não sendo apresentada nos gráficos confeccionados para expressar a colheita.

\section{RESULTADOS E DISCUSSÃO}

Os resultados decorrentes das avaliações nas parcelas experimentais, em função das aplicações do fungicida fluazinam em jato dirigido sobre os toletes de cana-de-açúcar, no sistema de plantio mecanizado, baseando-se no controle da podridão-abacaxi, são apresentados a seguir. 


\section{Avaliação do número e da percentagem de incremento de perfilhos de cana-de-açúcar}

Durante as avaliações iniciais, em algumas bordaduras das parcelas experimentais onde se verificaram falhas na brotação, desenterraram-se os toletes e verificou-se visualmente a presença da doença, conforme descrita por TOKESHI (2005).

Após a avaliação a campo e plotagem dos dados, observou-se correlação positiva entre o número de perfilhos e a concentração da calda aplicada (Figura 1). Na dose de 2,0 L ha ${ }^{-1}$, o número de perfilhos tende a se estabilizar, nas avaliações aos 30; 60 e 90 dias.

Observa-se, também, correlação significativa para a equação de regressão quadrática, exceto para a avaliação aos 120 dias após a emergência, quando os resultados se tornam menos uniformes, e o número de perfilhos estava, no geral, maior em todas as parcelas experimentais.
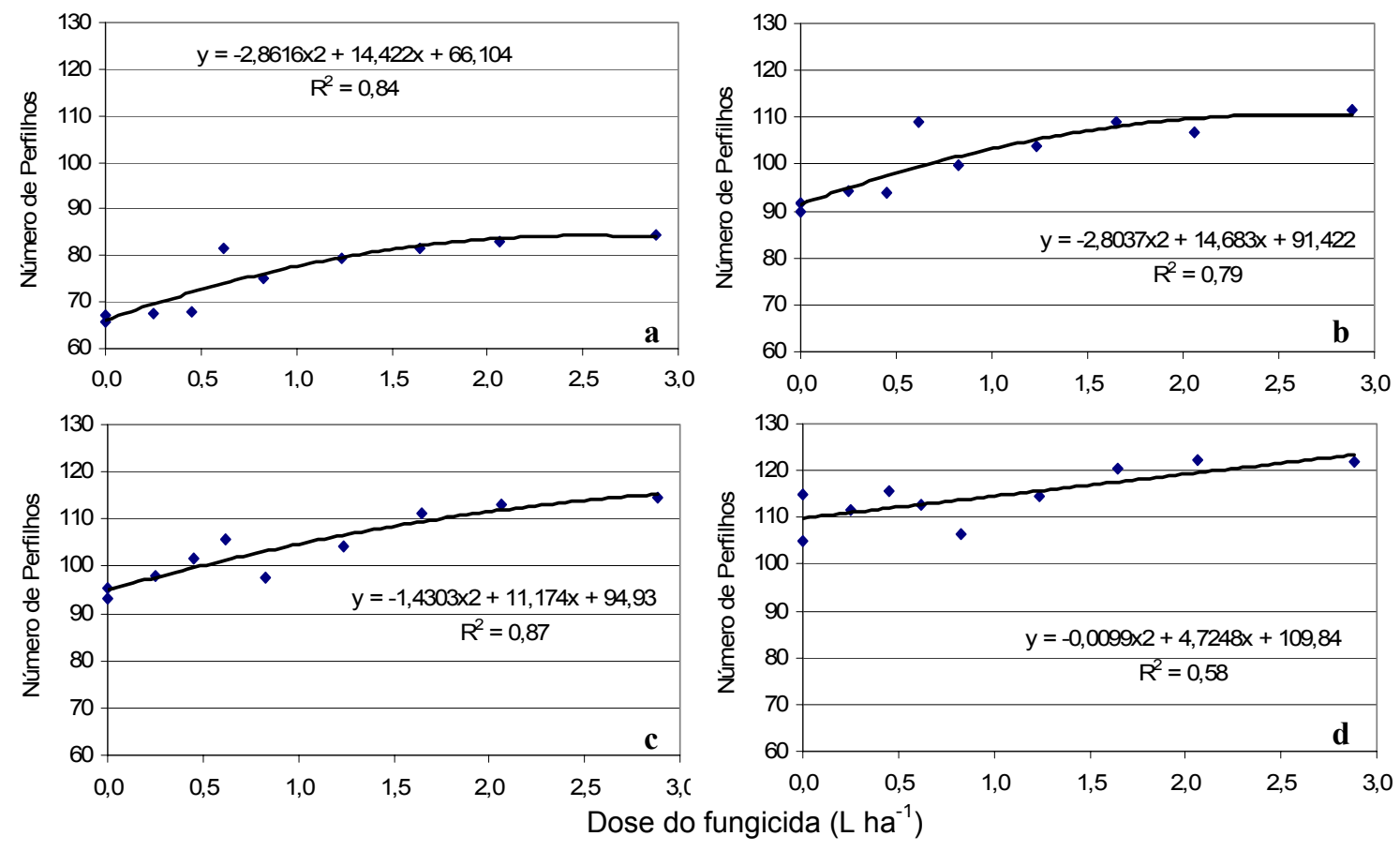

FIGURA 1. Número médio de perfilhos em $10 \mathrm{~m}$ lineares em relação à dose do fungicida aplicado com jato dirigido aos toletes de cana-de-açúcar em sistema de plantio mecanizado (a 30; b - 60; c - 90, e d - 120 dias após a emergência das plantas). Average of number of arises on ten linear meters in relation to fungicide rate, sprayed with a straighter fan on steams of sugarcane in mechanized planting system $(a-30 ; b-60 ; c-90$, and $\mathbf{d}$ - 120 days after the appearance of plants).

$\mathrm{Na}$ avaliação aos 120 dias após a emergência, a cana-de-açúcar já se apresentava bastante desenvolvida, o que dificultou a contagem dos perfilhos. Isso pode ter comprometido a avaliação. Aos 180 dias após a emergência, tentou-se avaliar novamente o número de perfilhos, porém os colmos das plantas da cana tomavam toda a entrelinha, o que impediu o caminhamento normal da avaliação e inviabilizou a aquisição desses dados.

O aumento constante do número de perfilhos da cana-de-açúcar ocorreu em todas as parcelas, independentemente do tratamento, tendendo à estabilização a medida que as plantas foram se desenvolvendo. Isso faz parte do comportamento biológico natural da cana-de-açúcar, durante o qual há perfilhamento constante das plantas presentes, diminuindo progressivamente com o autosombreamento da cultura e com a proximidade da fase de reprodução (UDOP, 2006). Esse número não apresenta necessariamente correlação significativa como a produtividade da cultura, uma vez que a qualidade das plantas advindas é comprometida devido à desvantagem competitiva, assim como aos perfilhos brotados de plantas doentes, em relação àqueles brotados primeiramente na área e provenientes de plantas sadias (TOKESHI, 2005). 
Para a percentagem de incremento do número de perfilhos em relação à testemunha inoculada com o fungo e não-tratada com o fungicida, observa-se, aos 30 dias após a emergência da cultura, aumento na percentagem de perfilhos conforme a concentração da calda aumenta, com tendência de estabilização a partir da dose de $0,62 \%$ do produto comercial na calda (Figura 2).

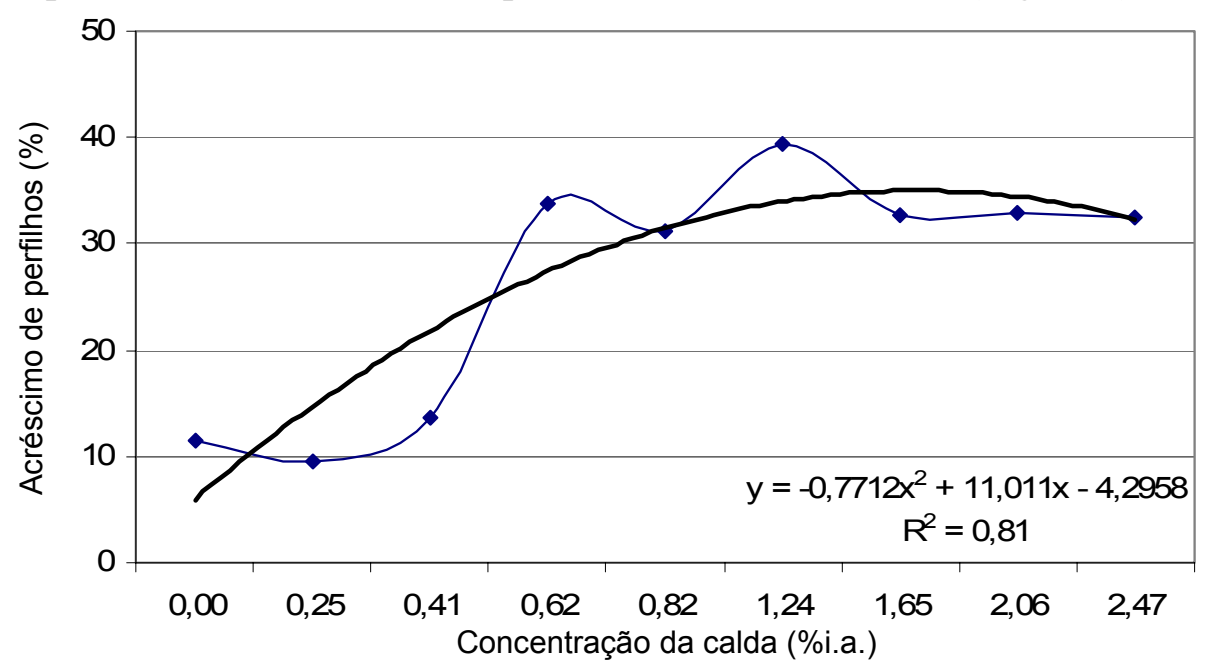

FIGURA 2. Percentagem de incremento do número de perfilhos em relação à testemunha sem a aplicação de fungicidas e inoculada com o fungo Thielaviopsis paradoxa, na avaliação aos 30 dias após a emergência da cultura. Percentage of increment in the number of arises in relation to the non treated with fungicide check plot but and inoculate with fungicide Thielaviopsis paradoxa, 30 days after the appearance of plants.

$\mathrm{Na}$ avaliação realizada aos 60 dias, houve aumento na percentagem de incremento de perfilhos, com o aumento da concentração do fungicida, com tendência de estabilização na mesma concentração do produto comercial observada na primeira avaliação (Figura 3).

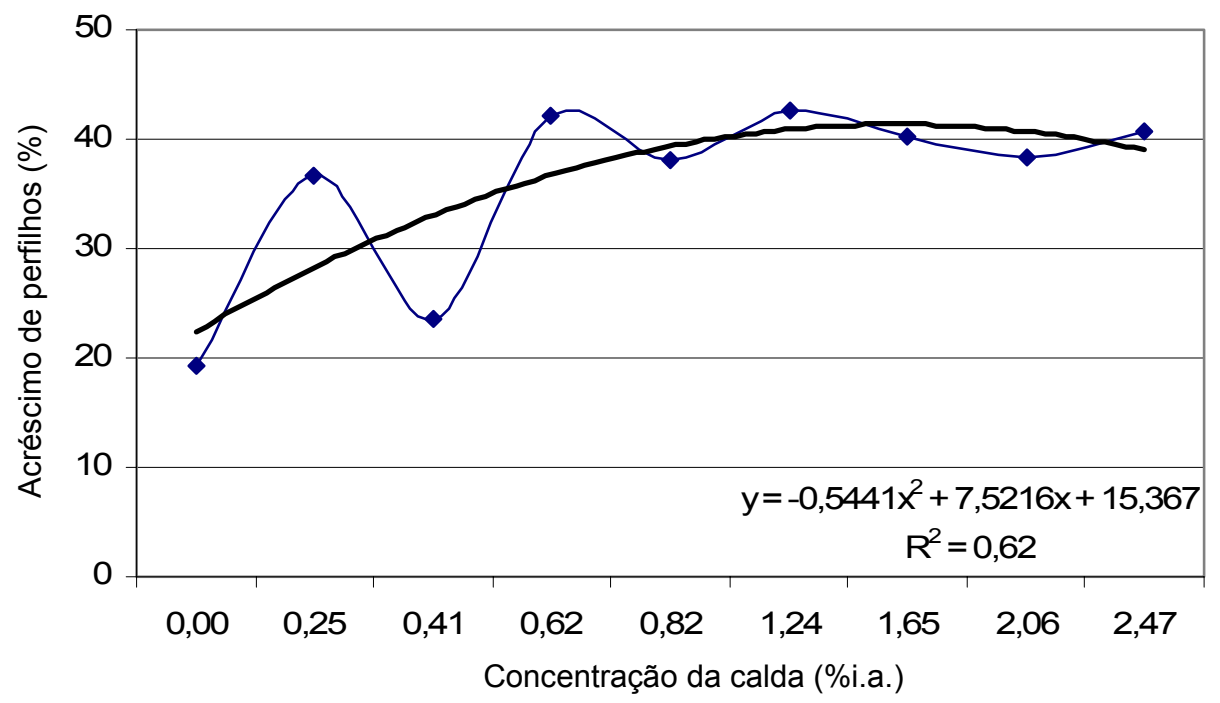

FIGURA 3. Percentagem de incremento do número de perfilhos em relação à testemunha sem a aplicação de fungicidas e inoculada com o fungo Thielaviopsis paradoxa, na avaliação aos 60 dias após a emergência da cultura. Percentage of increment in the number of arises in relation of the non treated with fungicide check plot but and inoculate with fungicide Thielaviopsis paradoxa, 60 days after the appearance of plants.

$\mathrm{Na}$ avaliação realizada aos 90 dias, como aconteceu nas duas primeiras avaliações, a percentagem de incremento do número de perfilhos aumentou com a concentração da calda aplicada. Entretanto, a tendência de estabilização agora ocorreu a partir de uma concentração maior, estando em torno de $1,65 \%$ do produto comercial na calda (Figura 4). 


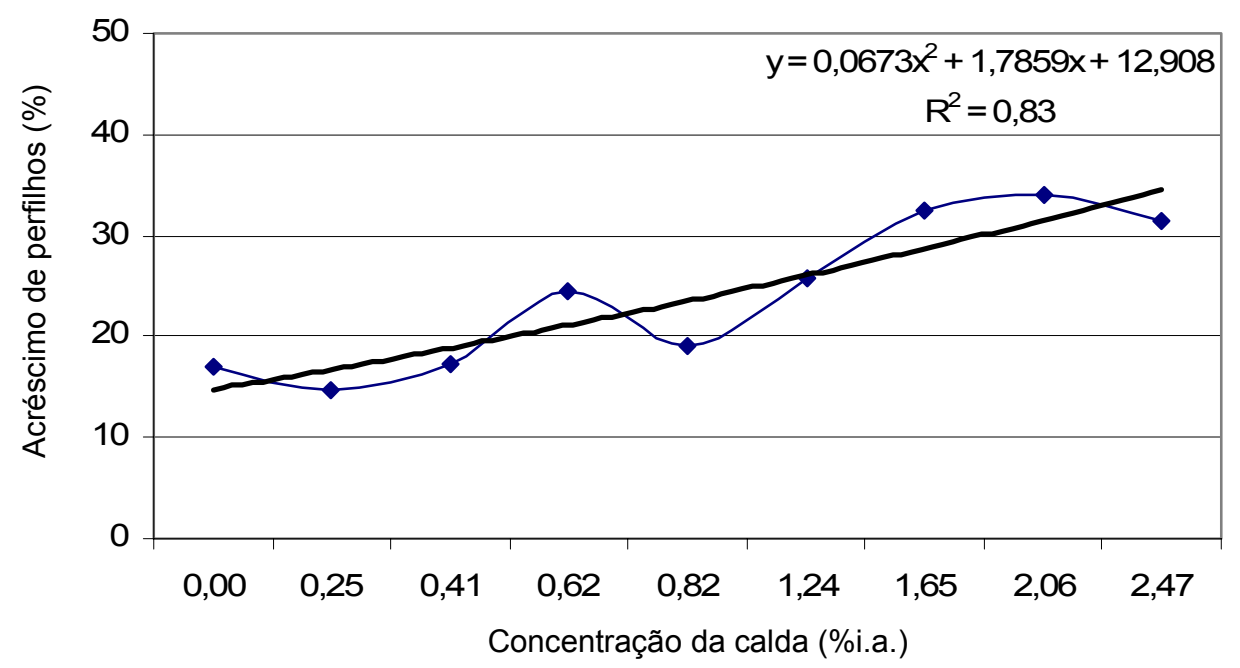

FIGURA 4. Percentagem de incremento do número de perfilhos em relação à testemunha sem a aplicação de fungicidas e inoculada com o fungo Thielaviopsis paradoxa, na avaliação aos 90 dias após a emergência da cultura. Percentage of increment in the number of arises in relation of the non treated with fungicide check plot but and inoculate with fungicide Thielaviopsis paradoxa, 90 days after the appearance of plants.

$\mathrm{Na}$ avaliação realizada aos 120 dias, houve certa uniformização da percentagem de incremento, assim como foi observado anteriormente para o número de perfilhos, sendo o incremento menor em relação à testemunha do que nas avaliações anteriores (Figura 5).

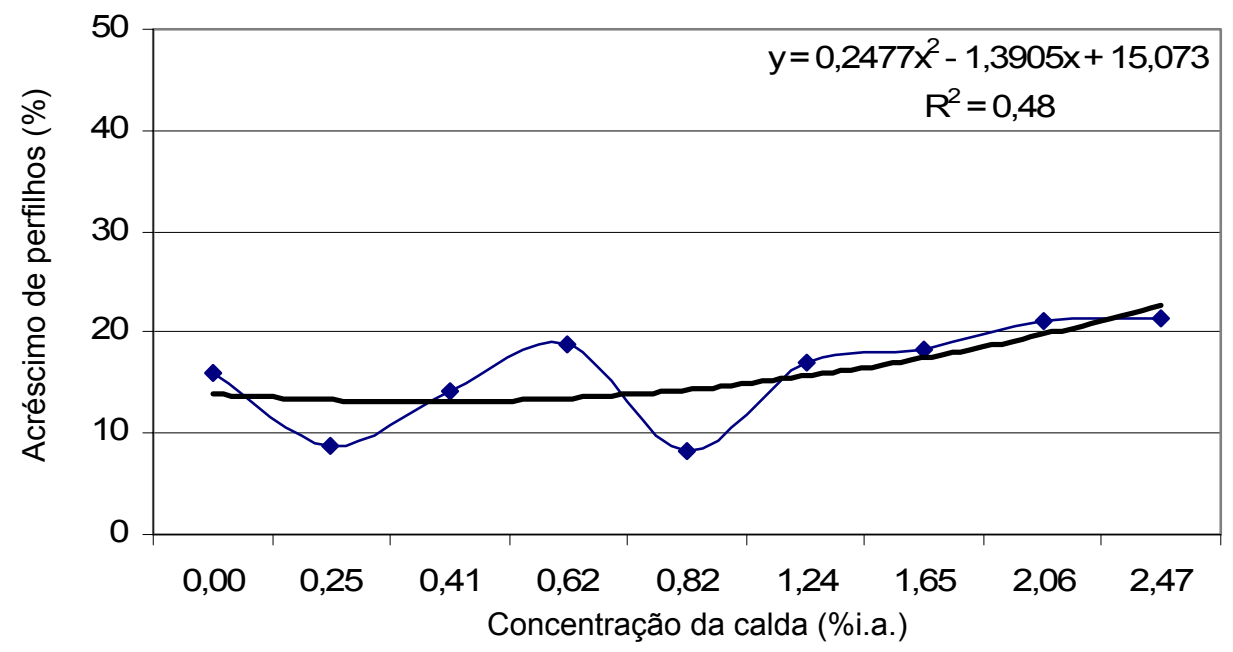

FIGURA 5. Percentagem de incremento do número de perfilhos em relação à testemunha sem a aplicação de fungicidas e inoculada com o fungo Thielaviopsis paradoxa, na avaliação aos 120 dias após a emergência da cultura. Percentage of increment in the number of arises in relation of the non treated with fungicide check plot but and inoculate with fungicide Thielaviopsis paradoxa, 120 days after the appearance of plants.

A estabilização da percentagem de perfilhos em relação à dose inicia-se na concentração de $1,24 \%$ de produto comercial na calda, consolidando-se a partir de 2,06\%.

De maneira geral, no experimento, os tratamentos resultaram em acréscimo no perfilhamento em relação à testemunha inoculada com o fungo. Foi observada tendência de estabilização do número de perfilhos a partir da concentração de $1,24 \%$ do produto comercial na calda, sendo mais consistente a partir de $1,65 \%$. A dose de $0,62 \%$ do produto comercial na calda foi recorrente, desde a primeira avaliação, em apresentar número de perfilhos equivalentes às maiores doses. Porém, isso 
não se sustenta teoricamente e pode ter ocorrido algum efeito casual que resultou em tal verificação. De qualquer forma, o mínimo de perfilhos manteve-se de acordo com os valores esperados e preconizados a campo, resultando entre 11 e 12 colmos por metro.

A utilização do método de imersão dos toletes para comparação do controle realizado pela aplicação via pulverização não demonstrou vantagem em relação ao perfilhamento, sendo verificada alguma diferença apenas em relação às doses.

\section{Avaliação de produtividade da cana-de-açúcar}

Pode-se verificar acréscimo na produtividade da cultura em função das doses do fungicida empregadas para o controle da podridão-abacaxi. Porém, o ponto referente à dose de $2,06 \%$ do fungicida na calda sofreu desvio da tendência, baixando o coeficiente de correlação entre os parâmetros (Figura 6).

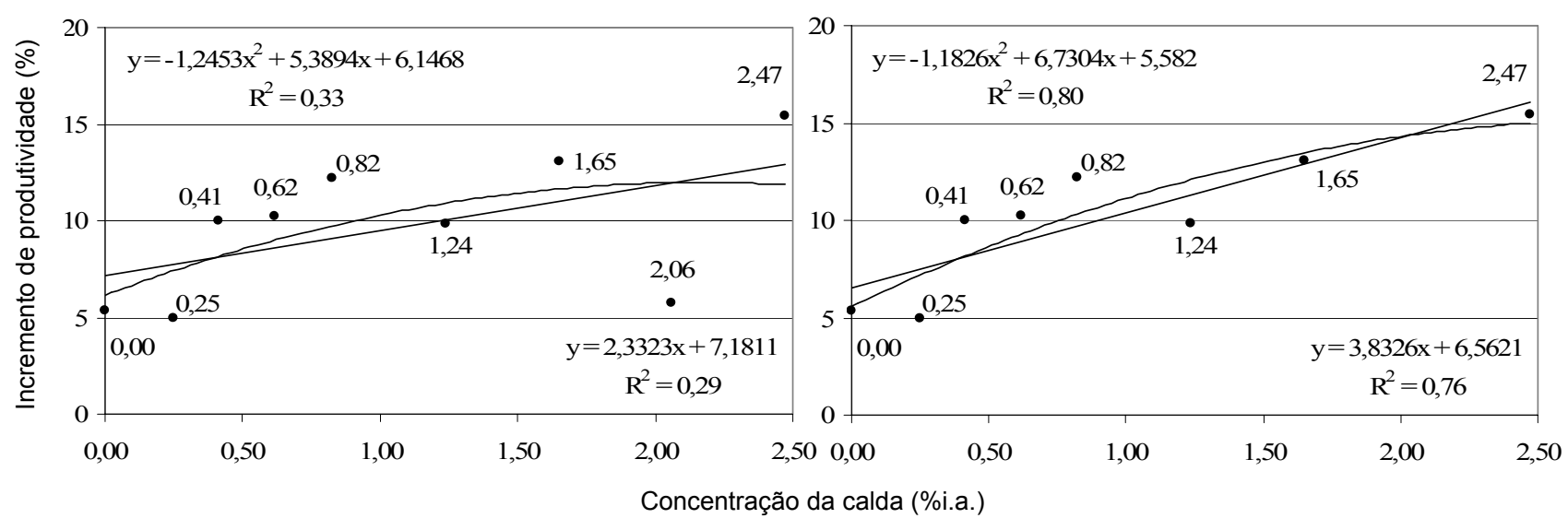

FIGURA 6. Percentagem de incremento de produtividade em relação à testemunha sem a aplicação de fungicidas e inoculada com o fungo Thielaviopsis paradoxa. Percentage of increment in productivity in relation of the non treated with fungicide check plot but and inoculate with fungicide Thielaviopsis paradoxa.

Considerando-se os valores estimados por meio das equações de regressão linear $\left(\mathrm{R}^{2}=0,76\right) \mathrm{e}$ quadrática $\left(\mathrm{R}^{2}=0,80\right)$, verifica-se que o referido ponto difere em mais de duas vezes o valor do desvio-padrão da amostra (Tabela 2). Dessa forma, pode ser considerado um "out layer", e a sua ocorrência, atribuída a fatores não-controlados a campo.

Verifica-se aumento em torno de $10 \%$ na produtividade da cultura para a concentração de $0,82 \%$ do fungicida na calda, e em torno de $15 \%$ para a concentração de $2,47 \%$. Nessa concentração, é possível que já se tenha ultrapassado o ponto de inflexão da curva de incremento na produtividade e, portanto, da dose ótima a ser recomendada.

Devido às dificuldades associadas ao processo de avaliação que não permitiram a obtenção de todos os pontos com maior grau de confiança, pode-se sugerir que a dose está entre 0,8 e 2,5\%, com boa possibilidade de estar em torno de 1,24\%. Porém, é adequado que se realizem mais experimentos para verificar qual é o intervalo mais adequado de recomendação da dose.

A pulverização de produtos fitossanitários com o modelo de ponta TP 8002E sobre toletes de cana-de-açúcar, realizada durante o plantio mecanizado, é possível e viável tecnicamente. Isso pode ser ressaltado pela comparação entre os tratamentos que utilizaram as concentrações de $0,25 \%$ e $0,41 \%$. Na primeira, os toletes foram mergulhados na calda do fungicida, minimizando qualquer risco de falha na cobertura. Na segunda concentração, a aplicação foi realizada via pulverização, conforme descrito no item Material e Métodos. Entre ambas, a maior dose resultou em melhor controle, refletindo na adequação da tecnologia utilizada para a aplicação. 
TABELA 2. Acréscimo percentual observado** e estimado pelas equações de regressão linear e quadrática, em função da concentração da calda fungicida utilizada em experimento para controle da podridão-abacaxi, na cultura da cana-de-açúcar. Perceptual increasing observed** and estimated by equations of linear and squared regression due to the concentration of fungicide on spray liquid sprayed to control pineapple rottenness in sugarcane crop.

\begin{tabular}{|c|c|c|c|}
\hline \multirow{2}{*}{$\begin{array}{c}\text { Concentração da } \\
\text { Calda (\% i.a.) }\end{array}$} & \multicolumn{3}{|c|}{ Acréscimo na Produtividade (\%) } \\
\hline & Valor Observado ${ }^{1}$ & Regressão Linear $^{2}$ & Regressão Quadrática $^{2}$ \\
\hline 0 & 5,3 & 6,6 & 5,6 \\
\hline 0,25 & 5,0 & 7,5 & 7,2 \\
\hline 0,41 & 10,0 & 8,1 & 8,1 \\
\hline 0,62 & 10,2 & 8,9 & 9,3 \\
\hline 0,82 & 12,2 & 9,7 & 10,3 \\
\hline 1,24 & 9,9 & 11,3 & 12,1 \\
\hline 1,65 & 13,1 & 12,9 & 13,5 \\
\hline 2,06 & 5,7 & 14,5 & 14,4 \\
\hline 2,47 & 15,4 & 16,0 & 15,0 \\
\hline
\end{tabular}

${ }^{1}$ Desvio-padrão dos dados observados $=3,7 ;{ }^{2}$ Valores estimados; $* *$ Base $=$ testemunha inoculada

A aplicação do fungo sobre os toletes de cana-de-açúcar promoveu diminuição na produtividade na ordem de $5 \%$ em relação à infestação natural. Porém, as doses acima de $0,4 \%$ já promoveram recuperação da produtividade sobre as testemunhas não-inoculadas de outros 5\%, corroborando a ocorrência natural de fungos na área experimental.

Pode-se considerar adequada a recomendação dos produtos fitosssanitários para a modalidade de aplicação conjugada ao plantio mecanizado da cana-de-açúcar para controle de pragas e doenças do solo, na forma de concentração do ingrediente ativo na calda, uma vez que a superfície coberta é o tolete. Sendo utilizada a tecnologia de aplicação corretamente, provavelmente serão obtidos durante o plantio mecanizado níveis bastante semelhantes de cobertura, resultando em dados comparáveis entre si, mesmo que ocorram pequenas variações durante a operação.

Práticas como o tratamento de toletes, o qual visa, especificamente, ao órgão suscetível à doença, com o objetivo de protegê-lo, com o mínimo impacto ao ambiente, podem contribuir para a sustentabilidade de cultivos com estratégias mais amigáveis econômica e ecologicamente.

Como é um dos primeiros trabalhos para tratamento de toletes em aplicação conjugada ao plantio mecanizado da cana-de-açúcar, é possível que alguns fatores não-controlados ainda tenham influenciado nos resultados. Dessa forma, sugere-se a repetição e o aprimoramento de experimentos com o mesmo sistema e finalidade para obter maior segurança na indicação de uso que possa garantir o número suficiente de perfilhos para boa produtividade da cana-de-açúcar durante o seu ciclo produtivo.

Variações na concentração da calda aplicada constituem-se em interessantes tratamentos para elucidar os aspectos técnicos da relação entre a cobertura, a distribuição e o controle da podridãoabacaxi, colaborando para o estudo da viabilidade econômica e na adoção comercial desse promissor e adaptado sistema de tratamento fitossanitário na cultura da cana-de-açúcar.

\section{CONCLUSÕES}

O sistema de pulverização para aplicação de produtos fitossanitários conjugado ao plantio mecanizado proporcionou recuperação da produtividade na cultura da cana-de-açúcar de até $15 \%$ $\left(\mathrm{em} \mathrm{tha}^{-1}\right.$ ), na maior dose utilizada para o controle da podridão-abacaxi, demonstrando ser promissor para o tratamento de toletes e visando à proteção contra doenças e pragas de solo. 


\section{AGRADECIMENTOS}

Ao setor de Fitopatologia do Departamento de Fitossanidade, do Câmpus de Jaboticabal da UNESP, pela produção das colônias do fungo T. paradoxa, e ao proprietário da área comercial de cana-de-açúcar que, gentilmente, apoiou e viabilizou o experimento a campo.

\section{REFERÊNCIAS}

AGROFIT. Disponível em: < http:// extranet. agricultura.gov.br/agrofit_cons /principal_agrofit . cons $>$. Acesso em: 30 abr. 2007.

ALFONSI, R.R.; PEDRO JÚNIOR, M.J.; BRUNINI, O.; BARBIERI, V. Condições climáticas para a cana-de-açúcar. In: PARANHOS, S.B. Cana-de-açúcar: cultivo e utilização. Campinas: Fundação Cargill, 1987. v.1, p.42-55.

BALASTREIRE, L.A. Máquinas agrícolas. São Paulo: Manole, 1990. 310 p.

CASAGRANDE, S.A. Tópicos de morfologia e fisiologia da cana-de-açúcar. Jaboticabal: FUNEP, 1991. $157 \mathrm{p}$.

CONAB. Companhia Nacional de Abastecimento. Cana-de-açúcar: safra 2005/2006 - terceiro levantamento. São Paulo, dez. 2005. Disponível em: <http:www.conab.gov.br/ safra $>$. Acesso em: 30 mar. 2005.

FERREIRA, M.C.; LEITE, G.J.; FURUHASHI, S. Cobertura de toletes de cana-de-açúcar pela calda, em pulverização conjugada ao plantio mecanizado. In: SIMPÓSIO INTERNACIONAL DE TECNOLOGIA DE APLICAÇÃO DE AGROTÓXICOS, 3., 2004, Botucatu. Anais... Botucatu: FEPAF, 2004. p.80-3.

MATUO, T. Técnicas de aplicação de defensivos agrícolas. Jaboticabal: FUNEP, 1990. 139 p. MOHANRAJ, D.; PADMANABAN, P.; VISWANATHAN, R. Biological control of sugarcane diseases. In: GNANAMANICKAN, S.S. (Ed.). Biological control of crop diseases. Chennai: CRC PRESS, 2002. p.161-78.

TOKESHI, H. Doenças da cana-de-açúcar (híbridos de Saccharum spp.). In: KIMATI, H.; AMORIM, L.; REZENDE, J.A.M.; BERGAMIN FILHO, A.; CAMARGO, L.E.A. Manual de fitopatologia: doenças das plantas cultivadas. 4.ed. São Paulo: Agronômica Ceres, 2005. v.2, p.20725 .

UDOP. ASSOCIAÇÃO PROFISSIONAL DA INDÚSTRIA DA FABRICAÇÃO DE ÁLCOOL, AÇÚCAR, SIMILARES E CONEXOS. Características mais marcantes das principais variedades de cana da região Centro-Sul. Disponível em http://www.udop.com.br/. Acesso em: 22 maio 2006. 